\title{
Diachronic Mapping of LUCC in the Northwest of China over the last half Century: Conversion of CORONA Panchromatic reflectance into LANDSAT NDVI Imagery
}

\author{
Frank Veroustraete ${ }^{1, *}$, Hui Fang ${ }^{2}$, Chen $\mathrm{Xi}^{2}$, An Ming Bao ${ }^{2}$, Qinghan Dong ${ }^{1}$, Liu Tie ${ }^{2,3}$ and \\ Patrick Willems ${ }^{3}$
}

1 Flemish Institute for Technological Research (VITO), Unit of Spatial and Environmental Aspects (RMA).Boeretang 200, BE2400 Mol, Belgium.

2 Xinjiang Institute for Ecology and GIS (XIEG). 40-3 South Beijing Road, Urumqi, Xinjiang 830011, China.

3 Catholic University of Leuven (K. U. Leuven), Department of Civil Engineering. Kasteelpark Arenberg 40, BE3001 Heverlee, Belgium.

* Author to whom correspondence should be addressed; Tel.: +32-14-336786; Fax: +32-14-322795; EMail: frank.veroustraete@vito.be

Received: 21 June 2011 / in revised form: 23 September 2011 / Accepted: 28 October 2011 /

Published: 22 November 2011

\begin{abstract}
It is only by using the first collection of intelligence satellite imagery acquired by CORONA, that time series of NDVI imagery can go back for a time period of nearly 50 years, based on diachronic mapping. This is an exceptionally long time period if not the longest, for which remote sensing imagery is available to estimate land use change for specific regions on the globe. The P.R. of China and the former USSR can be documented to nearly 50 years back in time, using CORONA satellite imagery. Typically - for many regions of the globe - is that a 50 year time span represents the principal time period in which many anthropogenic land use changes have taken place. In this paper, an account is given of the land use change which took place over the last 44 years in the Chinese province of Xinjiang, located in the North-west of the country. Declassified CORONA imagery was used, as well as LANDSAT MSS and ETM+ imagery. The Xinjiang province has one of the largest inland water basins on the globe, e.g. that of the Tarim river. Moreover, the province has grown into a major cotton and fruit producer in China. Based on diachronic mapping with CORONA and LANDSAT imagery, we can illustrate that over the last 44
\end{abstract}


years the Tarim river basin has undergone drastic land use changes, e.g., from nonfragmented landscapes of natural vegetation to fragmented mosaics of agrcicultural plots and desert. The region of interest in this study is the downstream area of the Tarim basin in the province of Xinjiang in the P.R. of China. A transfer function was established between canopy panchromatic reflectance $\left(\rho_{c, \text { pan }}\right)$ and canopy NDVI $\left(\mathrm{NDVI}_{\mathrm{c}}\right)$. This allows to reach the objective to increase the back casting time period of land use change observations based on satellite observations. To this end, a coupled PROSPECT-SAIL radiative transfer modelling approach was applied. Our approach elicited that the relationship between NDVI and $\rho_{\text {pan }}$ at leaf level, converges to a single relationship depending on leaf structure. The canopy level transfer function used to convert $\rho_{c, p a n}$ into $\mathrm{NDVI}_{c}$ was established using different chlorophyll contents, LAI values and a bright soil in the PROSPECT/SAIL radiative transfer models. A main result is that for a time lapse of 44 years, a drastic change in land use took place in the downstream reaches of the Tarim river basin. In many places natural vegetation has converted into high productivity irrigated agricultural plots. On the other hand natural vegetation also degraded into desert and semi-desert areas of very low to zero level productivity. A relatively small area (13\%) of the Tarim downstream area has remained unchanged during the course of 44 years. Typically, the radiation regime and especially the hydrology of the the Xinjiang province has changed significantly over the last 44 years due to this drastic land use change. During this period the Tarim river retracted upstream, several hundreds of $\mathrm{km}$, leaving behind desert land inapt for agricultural production and hence inapt to sustain human life.

Keywords: Diachronic mapping; CORONA sensor; NDVI; land use change; Xinjiang province; Tarim river basin.

\section{Introduction:}

Over the last centuries, human influence on land use turned into a global phenomenon (Turner et al., 1990 [1], Foley et al., 2005 [2]). Deforestation, but especially agricultural expansion and intensification, desertification, and urban sprawl, represent important global environmental issues today (Lepers et al. 2005[3]). About $40 \%$ of the global terrestrial surface is exploited for agricultural purposes (Foley et al. 2005[2]). Tropical deforestation, especially in the Amazon Basin and Southeast Asia (Lepers et al. 2005[3]), is an ongoing process leading to an increased fragmentation and biodiversity loss of tropical forests, making these systems more vulnerable to hazards like forest fires. Large-scale changes in land use and land cover do impact on regional and global climate, degrading freshwater resources, causing air pollution, inducing fragmented habitats which leads to a reduction in species even extinction and hence an important biodiversity loss. (Foley et al. 2005 [2]). Clearly, landuse and land-cover change (LUCC) can therefore be considered as a major driver of global change. 
LUCC regional environmental impacts are a threat for current and future generations. The lowering of groundwater tables, the retraction of rivers flowing into desert areas, problems of land and water contamination or salt accumulation lead to a reduced vegetation productivity. Clearly a better understanding of land and water use dynamics over the last 30 to 50 years is central to the debate of sustainability and durable development.

The advent of satellite data has revolutionized our ability to characterize global land cover and monitor land-use patterns. Satellite sensors offer a synoptic view of the Earth, as well as observations based on consistent measurements and methodologies to map the planet. Satellite data have been used to characterize patterns of land-use and land-cover change across the world at scales from a few meters to a few degrees in latitude by longitude depending on the platform/sensor tandem. The core objective of this paper is to corroborate, whether LUCC can be mapped over the last half century making use of remote sensing observations instead of (paper) maps or Atlas information. Our central objective therefore is to make use of CORONA data for part of the province of Xinjiang in the P.R. of China to demonstrate the potential of using the first satellite remote sensing observations. The high resolution panchromatic CORONA imagery has a track record going back 44 years from now.

The CORONA satellites (McDonald, 1997 [4) were operated from August 1960 to May 1972 and collected both intelligence and mapping imagery. The imaging resolution was originally $8 \times 8 \mathrm{~m}$, but was increased to up to $2 \times 2 \mathrm{~m}$ later on. Individual imagery on average covered an area of approximately $6.25 \times 75 \mathrm{~km}$. Operated for nearly 12 years, over 800,000 images were acquired with the CORONA sensors. The image collection includes $6900 \mathrm{~m}$ of film and 39,000 digital scans. All 800,000 CORONA images are now declassified and can be ordered through the USGS (U.S. Geological Survey [5]. The USGS distributes duplicates of CORONA film in all standard photo product types, and maintains a metadata archive on CORONA, with browsing quality images of most CORONA frames. Initially orbiting at heights between 165 and $460 \mathrm{~km}$, the sensors resolved imagery at ground surface level up to $7.5 \times 7.5 \mathrm{~m}$ in panchromatic (PAN) mode. The first CORONA imagery, represented high spatial resolution even compared with modern sensor systems. Today, these resolutions are still categorized in the High Spatial Resolution imagery class, comparable with for example IKONOS panchromatic imagery.

CORONA panchromatic (PAN) film, is sensitive to all colours in the visible part of the electromagnetic spectrum of the Sun. A PAN film therefore produces a grey level, high spatial resolution image, which is highly sensitive for incoming visible radiation. An essential step in diachronic mapping based on CORONA $7.5 \times 7.5 \mathrm{~m}$ imagery, is the conversion of CORONA PAN imagery into LANDSAT compatible NDVI imagery. This conversion can be performed by the coupled application of leaf and canopy radiative transfer models like PROSPECT (Jacquemoud and Baret, 1990 [6]) and SAIL (Verhoef, 1984 [7]).

The PAN band has a spectral range typically from 450 to $800 \mathrm{~nm}$. Figure 1 illustrates the recuperation of a CORONA film payload over the ocean after a satellite reconnaissance mission.

CORONA KH1 was the first US - film based - reconnaissance satellite. It was the first polar orbiting satellite of the US as well. The typical orbital characteristics are:

- From 198 to $901 \mathrm{~km}$ height;

- a $82.5^{\circ}$ equator crossing inclination;

- a payload mass of $779 \mathrm{~kg}$. 
Figure 1: Recovery of the Discoverer 14 satellite capsule, of the CORONA series.

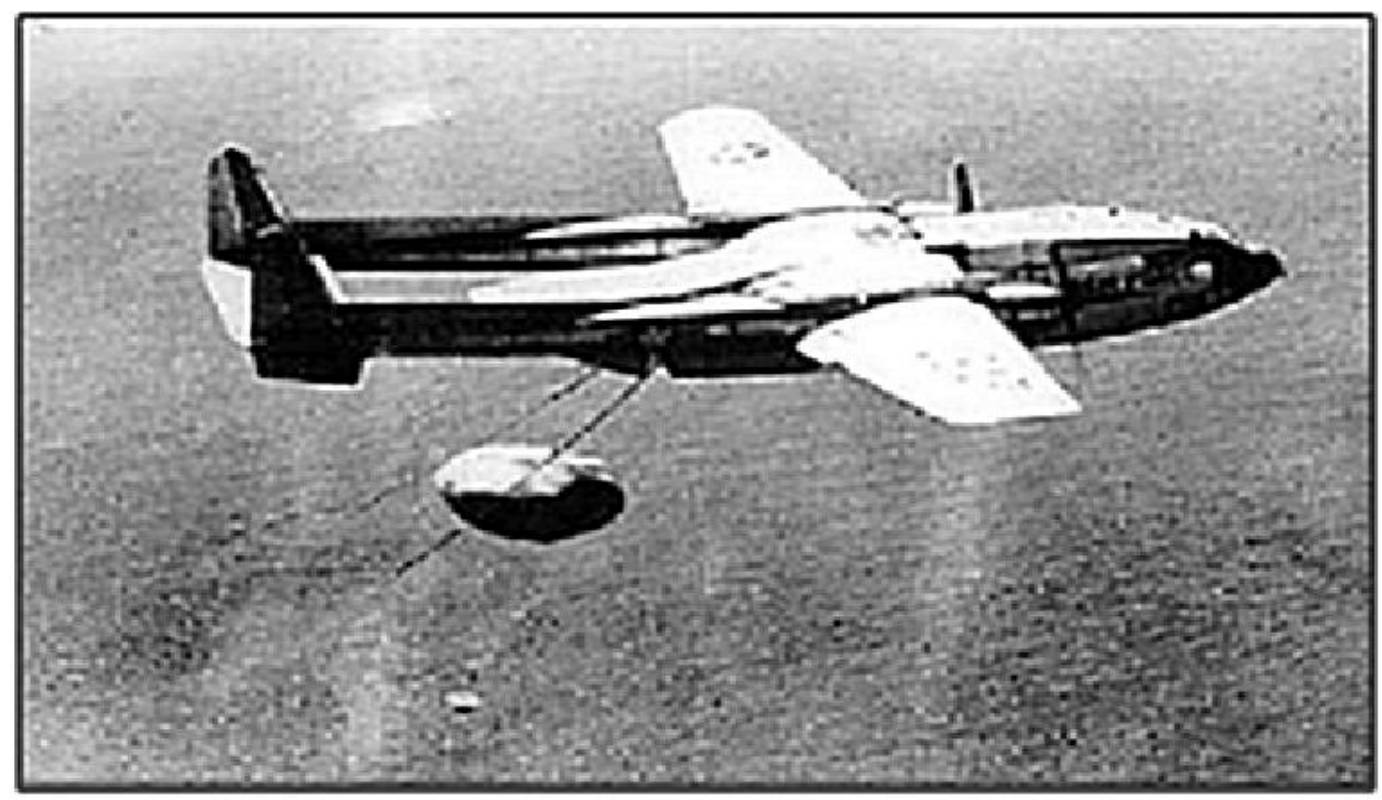

CORONA was a US military reconnaissance satellite system operated by the Central Intelligence Agency (CIA) Directorate of Science \& Technology with substantial assistance from USAF (the US Air Force). It was used for photographic surveillance in essentially the territories of China and the former Soviet Union from June 1959 until May 1972.

The CORONA satellites returned film canisters to Earth in capsules, called "buckets". They were recovered during their parachute descent in mid-air, by a specially equipped aircraft as illustrated in figure 1. The "buckets" were designed to be able to float in water for a short period of time to subsequently sink and evidently by then, considered as lost if the mid-air recovery failed.

In this paper the objective is to translate canopy reflectance in the PAN band into the NDVI at canopy level. The main reason for this is to be able to back cast further into the past using the vegetation index NDVI, which in the period where Corona was deployed was not commonly used. The earliest reported use of NDVI was in 1973 (Rouse et al.,1973 [11]). These authors were however preceded in the formulation itself of a normalized difference spectral index by Kriegler et al. in 1969 [12]. Soon after the launch of ERTS-1 (LANDSAT-1), Compton Tucker of NASA's Goddard Space Flight Center produced a series of early scientific journal articles describing uses of the NDVI Liming Zhou et al., 2004 [13]).

Hence, since continuity and consistency is important in diachronic image difference mapping, the NDVI is the first choice in back casting exercises for land use change going back to the sixties of the previous century. Clearly, the prime objective of the determination of a NDVI threshold as described in chapter 3.3., is to be able to decide whether vegetation has changed or not, primarily in cover fraction. Hence, discrimination between different types of vegetation is not the goal of this study. It goes without saying that this is only possible with multi-spectral or multi-temporal approaches. This is obviously impossible with panchromatic Corona data.

In the approach described in this paper, we used digitized CORONA frames acquired over the downstream area of the Tarim river in the Xinjiang province of the P.R. of China. Our results on LUCC estimation and diachronic mapping over the last 44 years led to estimates of a $45 \%$ increase in arable land, but concomitantly, a $42 \%$ increase in desert and semi-desert area. Only 13\% of the land 
cover in the downstream Tarim river area remained unchanged according to the boundary conditions we put forward. It goes without saying that the radiation regime and especially the hydrology of the region changed significantly over the last 44 years mainly due to the drastic land use changes observed.

In the next chapters, the methodology and results are described of how to convert CORONA panchromatic frames into LANDSAT compatible NDVI imagery, allowing a larger NDVI back cast in the framework of LUCC studies. Our work is conform with the conclusions from other studies observing that drastic changes in LUCC have taken place over the last 50 years, not only in the Chinese province of Xinjiang, but all over the globe (Lepers et al. 2005[3]).

\section{Materials:}

\subsection{Region of interest (ROI)}

Figure 2 illustrates the CORONA ROI with landscape photographs taken during the last 10 years from now. We can observe landscapes ranging from pure sandy deserts to river flood plains, covered with forested patches. Bright soils are omnipresent in this ROI.

Figure 2. In the upper left pane of the region of interest (ROI) of the CORONA imagery acquired during the year 1964 is delineated by the red markers and blue arrows pointing to the four corners of the superposed mosaic of Corona imagery. The ROI is located in the downstream area of the Tarim river which can be seen in the most SE photograph of the ROI (see red arrows). The panes with the photographs, illustrate the landscapes in the ROI as present over the last 10 years. The landscapes vary from flood planes to sandy desert areas. Bright soils are omnipresent in this ROI.

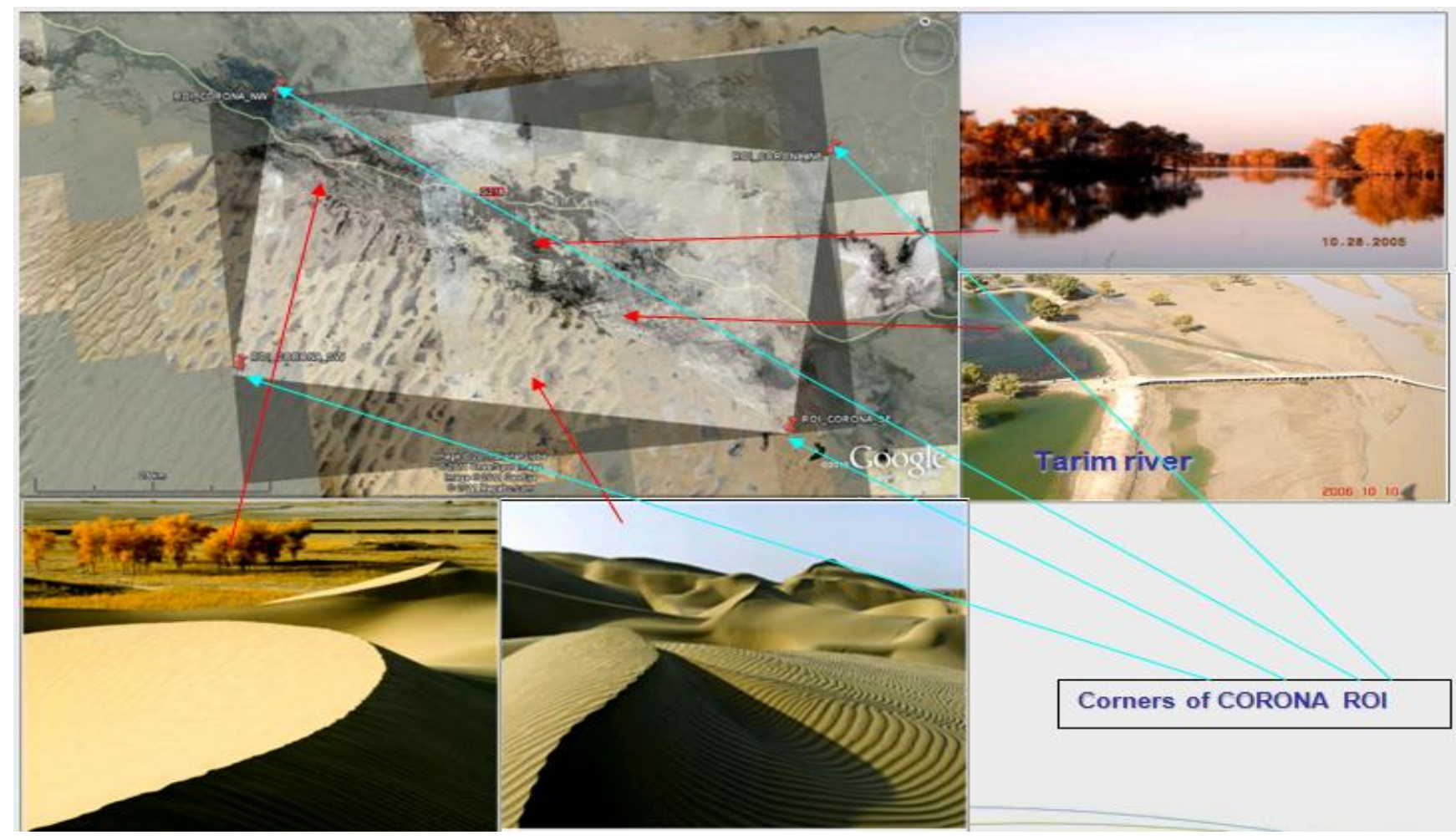


Table 1, summarises the region of interest (ROI) attributes for the area covered by CORONA imagery. The corners of the ROI are listed as well as the size of the ROI in pixels. The area per pixel equals $30 \times 30 \mathrm{~m}$.

\subsection{CORONA imagery used in this study}

Table 2 gives an overview of the CORONA frames selected in this study and used in diachronic mapping along with LANDSAT NDVI imagery, both datasets covering a time period of 44 years. These images all acquired in June 1964, have been stitched into one image spatial mosaic covering the ROI as described in the previous chapter and table 1.

Table 1. Definition of the region of interest (ROI) covered by CORONA frames for the land use change study. The corners of the ROI are listed as well as the size of the ROI in pixels. The area/pixel equals $30 \times 30 \mathrm{~m}$.

\begin{tabular}{|c|c|c|c|}
\hline $\begin{array}{l}\text { Upper left corner } \\
41^{\circ} 00^{\prime} 0.00^{\prime \prime} \mathrm{N} \\
86^{\circ} 45^{\prime} 0.00^{\prime \prime} \mathrm{E}\end{array}$ & ------------------ & ------------------ & $\begin{array}{c}\text { Upper right corner } \\
40^{\circ} 50^{\prime} 0.00^{\prime \prime} \mathrm{N} \\
87^{\circ} 31^{\prime} 0.00^{\prime \prime} \mathrm{E}\end{array}$ \\
\hline [ & & & ] \\
\hline $\begin{array}{c}\text { Lower left corner } \\
40^{\circ} 42^{\prime} 0.00^{\prime \prime} \mathrm{N} \\
86^{\circ} 38^{\prime} 0.00^{\prime \prime} \mathrm{E}\end{array}$ & & & $\begin{array}{c}\text { Lower right corner } \\
40^{\circ} 33^{\prime} 0.00^{\prime \prime} \mathrm{N} \\
87^{\circ} 24^{\prime} 0.00^{\prime \prime} \mathrm{E}\end{array}$ \\
\hline & $\begin{array}{r}\text { N-S axis }(\mathbf{k m}) \\
\text { W-E axis }(\mathbf{k m}) \\
\text { ROI }\left(\mathbf{k m}^{2}\right) \\
\text { Pixels/ROI (nr) } \\
\text { area/pixel }\left(\mathrm{m}^{2}\right) \\
\text { area/pixel }(\mathrm{m})\end{array}$ & $\begin{array}{r}31 \\
61 \\
1877 \\
2085525 \\
900 \\
30 \times 30\end{array}$ & \\
\hline
\end{tabular}


Table 2: List of CORONA frames used in this study, including their ID's, acquisition dates, mission and frame numbers as well as camera resolution and type.

\begin{tabular}{|c|c|c|c|c|c|c|c|}
\hline $\mathrm{Nr}$ & Entity ID & Acquisition & Mission Nr & Revolution & Frame Nr & Camera Resolution & Camera Type \\
\hline 1 & DS1006-1054DF030 & $08 / 06 / 1964$ & $1006-1$ & 054D & 30 & Stereo Medium & Forward \\
\hline 2 & DS1006-1054DF032 & 08/06/1964 & $1006-1$ & 054D & 32 & Stereo Medium & Forward \\
\hline 3 & DS1006-1054DF033 & 08/06/1964 & $1006-1$ & 054D & 33 & Stereo Medium & Forward \\
\hline 4 & DS1006-1054DF037 & 08/06/1964 & $1006-1$ & 054D & 37 & Stereo Medium & Forward \\
\hline 5 & DS1006-1054DF038 & 08/06/1964 & $1006-1$ & 054D & 38 & Stereo Medium & Forward \\
\hline 6 & DS1006-1054DF040 & $08 / 06 / 1964$ & $1006-1$ & 054D & 40 & Stereo Medium & Forward \\
\hline 7 & DS1006-1054DF041 & 08/06/1964 & $1006-1$ & 054D & 41 & Stereo Medium & Forward \\
\hline 8 & DS1006-1054DF043 & 08/06/1964 & $1006-1$ & 054D & 43 & Stereo Medium & Forward \\
\hline 9 & DS1006-1054DF045 & $08 / 06 / 1964$ & $1006-1$ & 054D & 45 & Stereo Medium & Forward \\
\hline 10 & DS1006-1054DF046 & 08/06/1964 & $1006-1$ & 054D & 46 & Stereo Medium & Forward \\
\hline 11 & DS1006-1054DF034 & 08/06/1964 & $1006-1$ & 054D & 34 & Stereo Medium & Forward \\
\hline 12 & DS1006-1054DF042 & $08 / 06 / 1964$ & $1006-1$ & 054D & 42 & Stereo Medium & Forward \\
\hline 13 & DS1006-1054DF031 & 08/06/1964 & $1006-1$ & 054D & 31 & Stereo Medium & Forward \\
\hline 14 & DS1006-1054DF036 & $08 / 06 / 1964$ & $1006-1$ & 054D & 36 & Stereo Medium & Forward \\
\hline 15 & DS1006-1054DF039 & 08/06/1964 & $1006-1$ & 054D & 39 & Stereo Medium & Forward \\
\hline 16 & DS1006-1054DF044 & 08/06/1964 & $1006-1$ & 054D & 44 & Stereo Medium & Forward \\
\hline 17 & DS1006-1054DF035 & 08/06/1964 & $1006-1$ & 054D & 35 & Stereo Medium & Forward \\
\hline 18 & DS1006-1054DF047 & 08/06/1964 & $1006-1$ & 054D & 47 & Stereo Medium & Forward \\
\hline 19 & DS1006-2070DF109 & 09/06/1964 & $1006-2$ & 070D & 109 & Stereo Medium & Forward \\
\hline 20 & DS1006-2070DF110 & 09/06/1964 & $1006-2$ & 070D & 110 & Stereo Medium & Forward \\
\hline 21 & DS1006-2070DF111 & 09/06/1964 & $1006-2$ & 070D & 111 & Stereo Medium & Forward \\
\hline 22 & DS1006-2070DF112 & 09/06/1964 & $1006-2$ & 070D & 112 & Stereo Medium & Forward \\
\hline 23 & DS1006-2070DF113 & 09/06/1964 & $1006-2$ & 070D & 113 & Stereo Medium & Forward \\
\hline 24 & DS1006-2070DF115 & 09/06/1964 & $1006-2$ & 070D & 115 & Stereo Medium & Forward \\
\hline 25 & DS1006-2070DF116 & 09/06/1964 & $1006-2$ & 070D & 116 & Stereo Medium & Forward \\
\hline 26 & DS1007-1054DF095 & $23 / 06 / 1964$ & $1007-1$ & 054D & 95 & Stereo Medium & Forward \\
\hline 27 & DS1007-1054DF097 & $23 / 06 / 1964$ & $1007-1$ & 054D & 97 & Stereo Medium & Forward \\
\hline 28 & DS1007-1054DF098 & $22 / 06 / 1964$ & $1007-1$ & 054D & 98 & Stereo Medium & Forward \\
\hline 29 & DS1007-1054DF096 & $23 / 06 / 1964$ & $1007-1$ & 054D & 96 & Stereo Medium & Forward \\
\hline 30 & DS1007-1054DF099 & $22 / 06 / 1964$ & $1007-1$ & 054D & 99 & Stereo Medium & Forward \\
\hline 31 & DS1007-1054DA100 & $23 / 06 / 1964$ & $1007-1$ & 054D & 100 & Stereo Medium & $\mathrm{AFT}$ \\
\hline 32 & DS1007-1054DA104 & $22 / 06 / 1964$ & $1007-1$ & 054D & 104 & Stereo Medium & AFT \\
\hline 33 & DS1007-1054DA105 & $23 / 06 / 1964$ & $1007-1$ & 054D & 105 & Stereo Medium & AFT \\
\hline 34 & DS1007-1054DA106 & $22 / 06 / 1964$ & $1007-1$ & 054D & 106 & Stereo Medium & AFT \\
\hline 35 & DS1007-1054DA102 & $23 / 06 / 1964$ & $1007-1$ & 054D & 102 & Stereo Medium & AFT \\
\hline 36 & DS1007-1054DA103 & $22 / 06 / 1964$ & $1007-1$ & 054D & 103 & Stereo Medium & AFT \\
\hline 37 & DS1007-1054DA101 & $23 / 06 / 1964$ & $1007-1$ & 054D & 101 & Stereo Medium & AFT \\
\hline
\end{tabular}

\section{Results}

\subsection{Modelling methodology to convert canopy PAN reflectance into canopy NDVI}

\subsubsection{Introduction}

A transfer function was established between canopy panchromatic reflectance $\left(\rho_{\mathrm{c}, \text { pan }}\right)$ and canopy NDVI $\left(\mathrm{NDVI}_{\mathrm{c}}\right)$ imagery. To this end, a coupled PROSPECT-SAIL model was applied. A boundary condition was defined for the leaf model specifying a minimum of 5 leaf cell layers. This allows for the conversion $\rho_{c, \text { pan }}$ as acquired with CORONA, into $\mathrm{NDVI}_{\mathrm{c}}$ imagery spatially and spectrally compatible with $\mathrm{NDVI}_{\mathrm{c}}$ imagery as obtained with LANDSAT.

The $\rho_{c, p a n}-\mathrm{NDVI}_{\mathrm{c}}$ image transfer function as well as the $\mathrm{NDVI}_{\mathrm{c}}$ threshold value for diachronic analysis by image differencing, have been calculated applying leaf and canopy radiative transfer models with different Artemisia species. Artemisia spp. are typical desert and semi-desert plant species in the Xinjiang province. 


\subsubsection{Leaf level}

The simulation scenario for simulations with PROSPECT and SAIL is as defined here below.

Simulation scenario of, at leaf NDVI $\left(\mathrm{NDVI}_{1}\right)$ in function of leaf PAN reflectance $\left(\rho_{\mathrm{l}, \mathrm{pan}}\right)$ is given hereunder:

a) Variable N: Number of cell layers $\mathrm{N}$ (between 2 and 10).

b) Variable $\mathrm{C}_{\mathrm{ab}}$ : Leaf chlorophyll $\mathrm{a}+\mathrm{b}$ content (range 0 to100) $\left[\mu \mathrm{g} / \mathrm{cm}^{2}\right]$.

c) Constant $\mathrm{C}_{\mathrm{w}}$ : Leaf water content $(0.02)\left[\mathrm{g} / \mathrm{cm}^{2}\right]$.

d) Constant $\mathrm{C}_{\mathrm{c}}$ : Leaf cellulose content $(0.01)\left[\mathrm{g} / \mathrm{cm}^{2}\right]$.

Figure 3. Relationship between $\mathrm{NDVI}_{1}$ and $\rho_{\mathrm{l} \text {,pan }}$, for different chlorophyll contents and values of $\mathrm{N}$. It can be observed that for values of $\mathrm{N}$ less than 5 , the linearity and slope stability of the $\mathrm{NDVI}_{1}$ and $\rho_{\mathrm{l}, \mathrm{pan}}$, transfer function is lost.

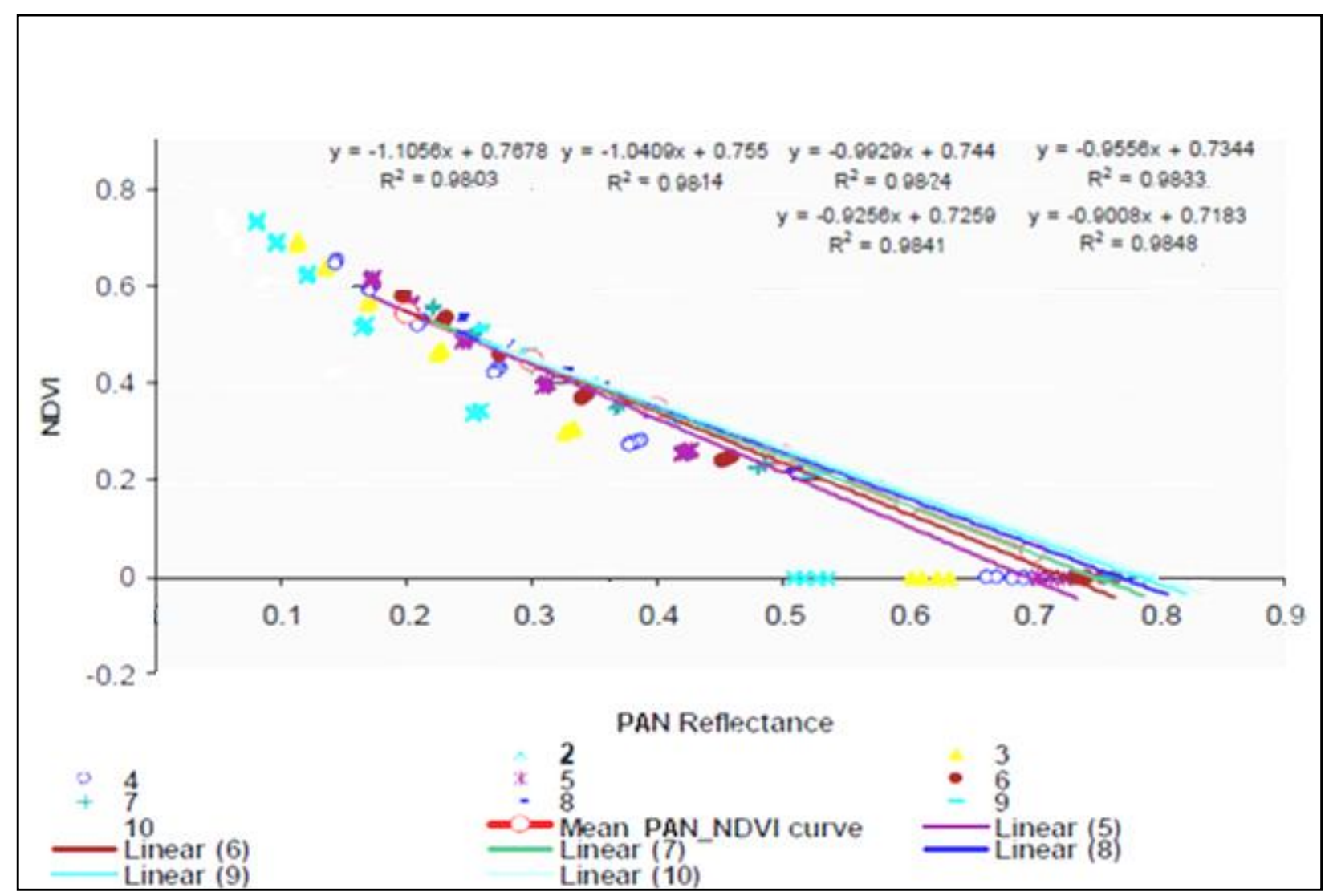

In figure 3 the results of the scenario described earlier is illustrated. It is elicited that the relationship between $\mathrm{NDVI}_{1}$ and $\rho_{\mathrm{l}, \mathrm{pan}}$, converges to a single relationship with values of $\mathrm{N}$ larger or equal to 5 . In table 3 , for 5 to 10 cell layers, low relative standard deviations on the slopes and intercepts of the $\mathrm{NDVI}_{1}-\rho_{\mathrm{l} \text {,pan }}$ relationships can be observed, respectively of 8.1 and $2.7 \%$. Hence, an average relationship for different leaf layer numbers within the boundary conditions put forward can be established, allowing the conversion of CORONA $\rho_{1, p a n}$ imagery into $\mathrm{NDVI}_{1}$ imagery. 
Table 3. Statistics of the leaf level NDVI vs PAN leaf reflectance relationships (see figure 3) in function of the internal structure parameter $\mathrm{N}$ of the PROSPECT model.

\begin{tabular}{|c|rccr|}
\hline $\mathrm{N}$ & Slope & Intercept & PAN & NDVI \\
\cline { 2 - 5 } 5 & -1.1056 & 0.7678 & 0.20 & 0.5435 \\
6 & -1.0409 & 0.7550 & 0.30 & 0.4448 \\
7 & -0.9929 & 0.7440 & 0.40 & 0.3461 \\
8 & -0.9556 & 0.7344 & 0.50 & 0.2475 \\
9 & -0.9256 & 0.7259 & 0.60 & 0.1488 \\
10 & -0.9008 & 0.7183 & 0.70 & 0.0501 \\
Average & -0.9869 & 0.7409 & & \\
Stdev & 0.08 & 0.02 & & \\
\hline
\end{tabular}

Figure 4 illustrates the transfer function (equation (1)), to convert leaf level PAN reflectance from CORONA imagery, into leaf level NDVI $\left(\mathrm{NDVI}_{1}\right)$. The leaf level transfer equation (1) as obtained with PROSPECT is:

$$
\mathrm{NDVI}_{1}=2.923 \rho_{1, \mathrm{pan}}^{2}-5.26 \rho_{\mathrm{l}, \mathrm{pan}}+1.592
$$

Figure 4. Transfer function for the conversion of $\rho_{\mathrm{l}, \mathrm{pan}}$ into $\mathrm{NDVI}_{\mathrm{l}}$, established with the PROSPECT leaf radiative transfer model using different leaf chlorophyll contents (cfr. leaf simulation scenario).

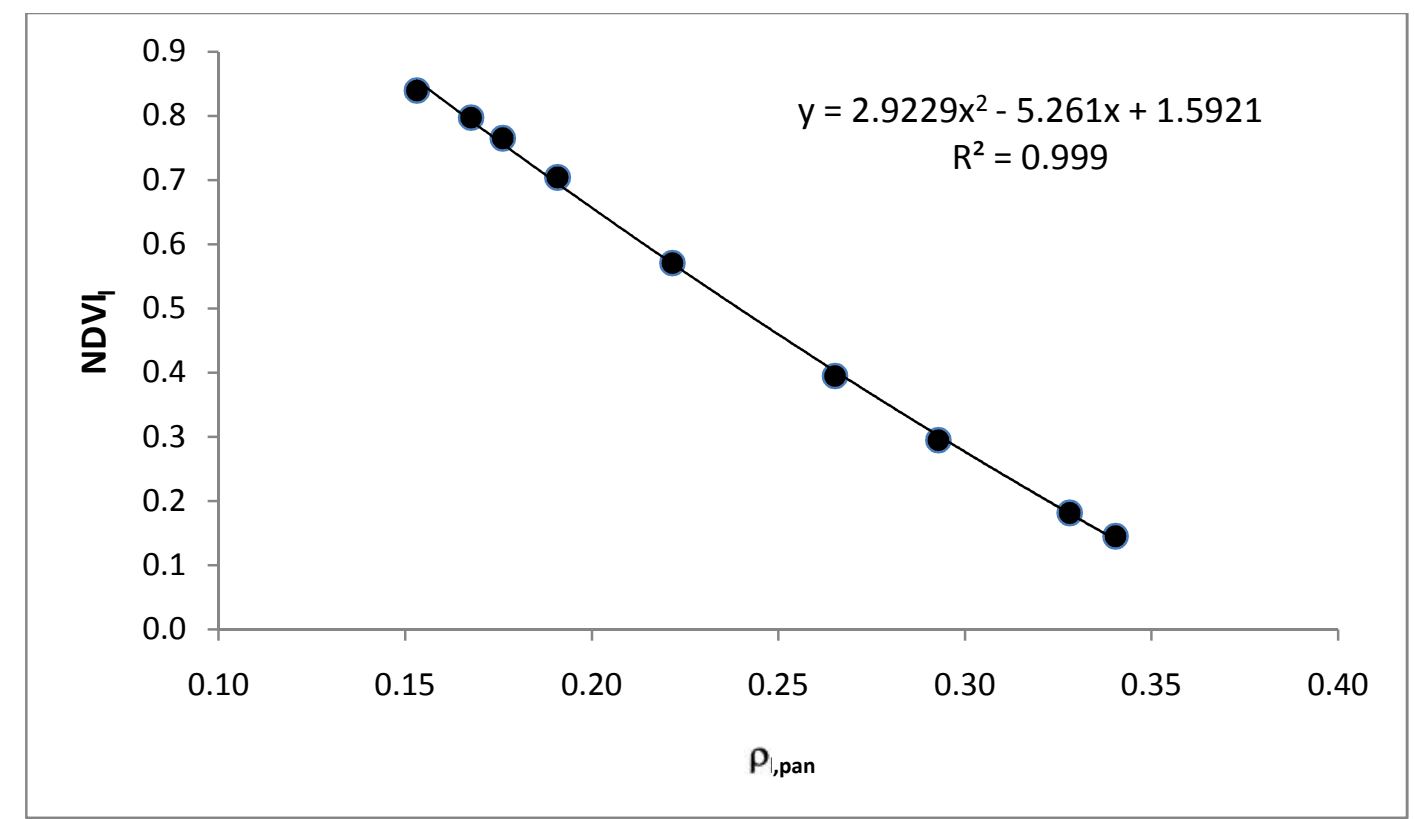




\subsubsection{Canopy level transfer function obtained with SAIL}

On the plateaus, mountain and river plains of the downstream Tarim river area, a shrub-like vegetation with short stems of mainly Sagebrush (Artemisia spp.), Tamarix and a number of grass species occur (Tariq Aftab et al., 2010 [8]). Growth of the perennial Artemisia and annual herbs and some grasses in the deserts and semi-deserts of the province is sparse to very sparse. The semi-desert zone vegetation is somewhat more abundant and also elicits dominance of the Artemisia and Tamarix herb class.

To define the transfer function between PAN canopy reflectance $\left(\rho_{c, p a n}\right)$ and the NDVI at the top of the canopy $\left(\mathrm{NDVI}_{\mathrm{c}}\right)$, the canopy level simulation scenario uses the leaf reflectance and transmittance signatures obtained as output from the PROSPECT (Jacquemoud et al., 1990 [6]) leaf radiative transfer model, as input for the canopy radiative transfer model SAIL (Verhoef, 1984 [7]).

In the canopy radiative transfer scenario, the range of leaf total chlorophyll content was chosen between 0.5 and $50 \mu \mathrm{g} / \mathrm{cm}^{2}$ (Aftab et al, 2010, [8]). The canopy scenario simulations are performed with bright soils of which the spectral signature is illustrated in figure 5 by the blue line (Nagler et al., 2000, [9]).

Figure 5. Spectral signatures of soils ranging from bright to dark used in the canopy radiative transfer model SAIL.

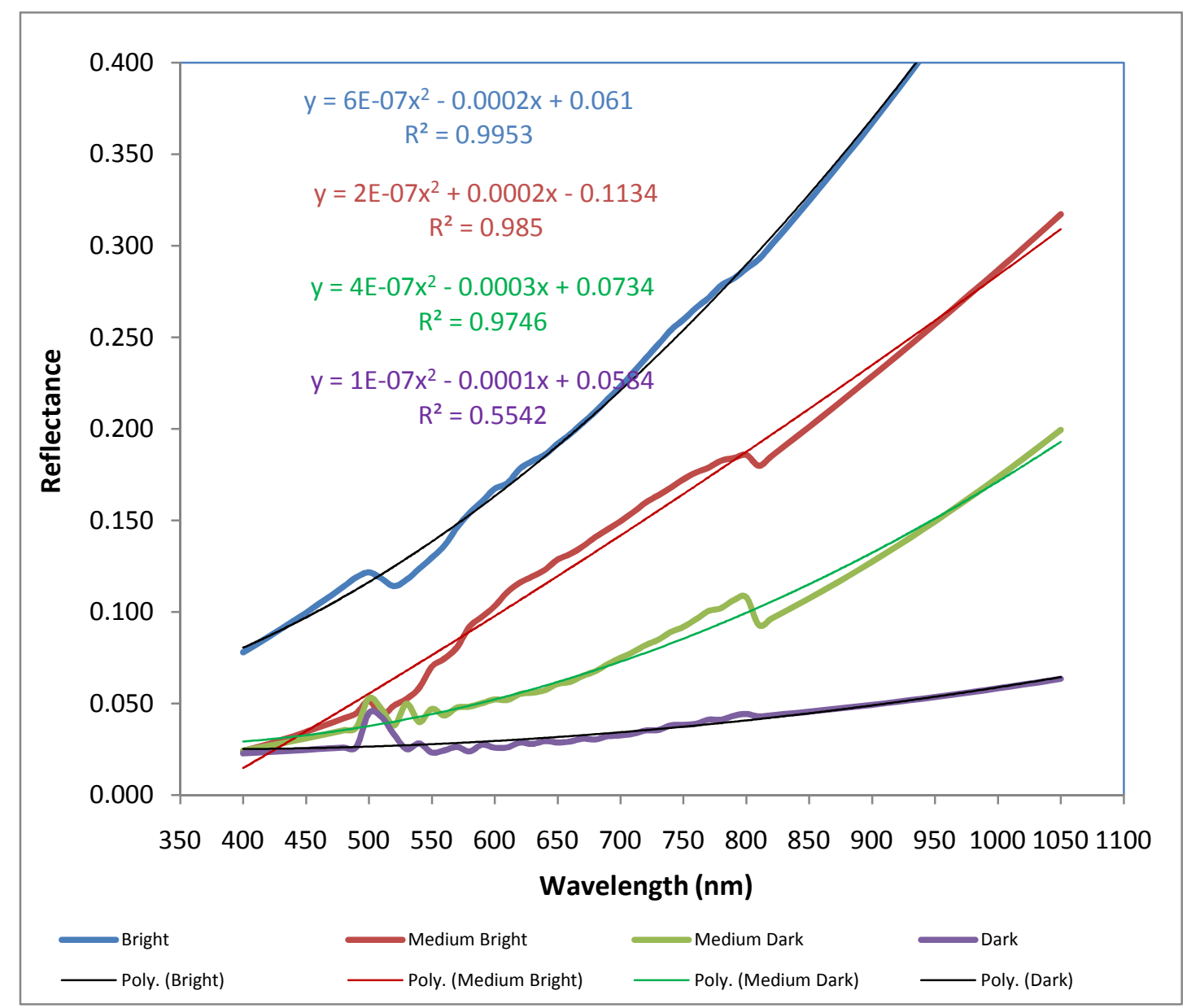


A typical total chlorophyll value of Artemisia spp. is $5 \mu \mathrm{g} / \mathrm{cm}^{2}$ [Aftab et al, 2010 [8]). The spectral signature for canopy reflectance obtained using this leaf chlorophyll value and using different LAI values as well as the bright soil signature typical for desert and semi-desert areas in the SAIL model, is illustrated in figure 6 .

By definition the PAN band covers all colours in the visible part of the EM spectrum. Hence, it covers the range between about 450 and $800 \mathrm{~nm}$. Figure 6 typically elicits the behaviour of vegetation growing on a bright soil. Hence spectral reflectance is equal to the soil line in the chlorophyll absorption bands around 400 and $660 \mathrm{~nm}$ (represented by the gray line at a LAI of 0.01 in Figure 6). For the other spectral ranges we can observe and increase in canopy reflectance above the soil reflectance line. When integrating reflectance for the PAN band, this leads to the relationship as illustrated in Figure 7 and equation (2).

Figure 6. Spectral signatures of canopy spectral reflectance for an Artemisia spp. leaf chlorophyll value of $5 \mu \mathrm{g} / \mathrm{cm}^{2}$ and LAI values ranging from 0.01 till 7. It can be observed that the bright soil line is quite dominant in this spectral signature. The soil spectral signature is modulated increasingly with higher canopy LAI values.

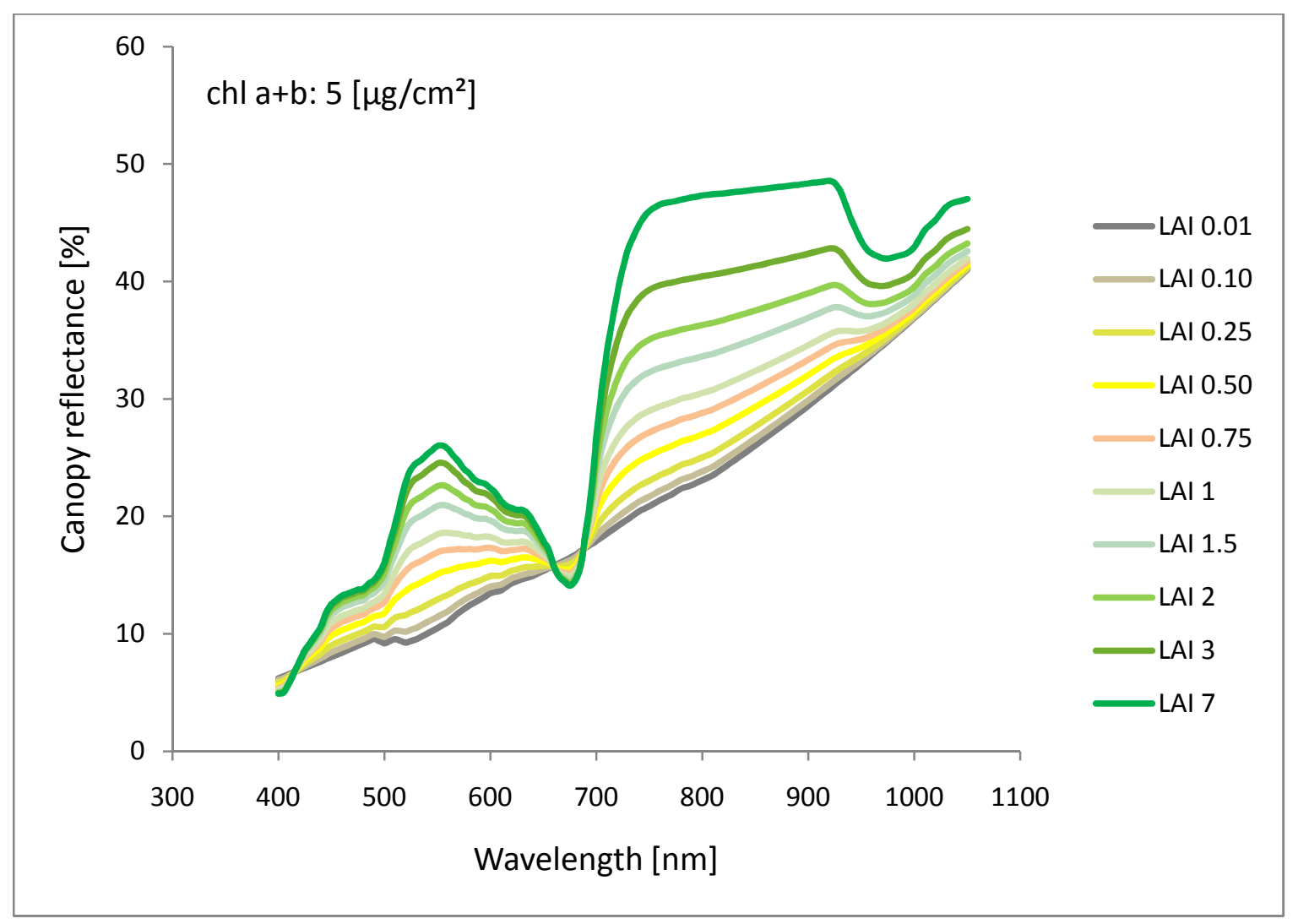

The canopy transfer function converting $\rho_{\mathrm{c}, \text { pan }}$ into $\mathrm{NDVI}_{\mathrm{c}}$ is illustrated in figure 7. 
Figure 7. Canopy level transfer function used to convert $\rho_{c \text {,pan }}$ into NDVI $I_{c}$. This function has been established with the PROSPECT and SAIL models using different chlorophyll contents, LAI values and a bright sandy soil.

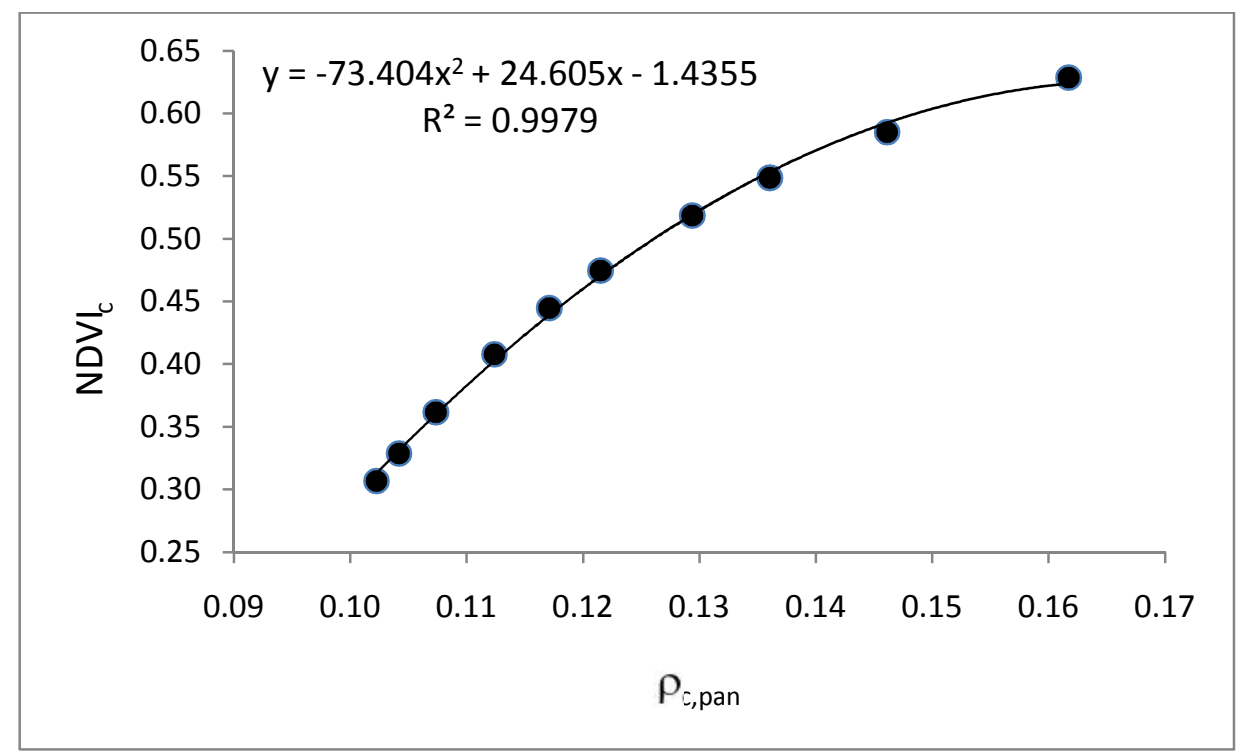

The canopy level transfer function (2) as obtained with PROSPECT - SAIL is:

$$
\mathrm{NDVI}_{\mathrm{c}}=73.4 \rho_{\mathrm{c}, \mathrm{pan}}^{2}+24.6 \rho_{\mathrm{c}, \mathrm{pan}}-1.436
$$

This transfer function is applied to convert CORONA PAN reflectance into $\mathrm{NDVI}_{\mathrm{c}}$ imagery.

\subsection{Application of the canopy transfer function to estimate changes in Land Use}

In figure 8 it can be observed that for a time lapse of 44 years, a drastic change in land use took place in the downstream reaches of the Tarim river basin (see figure 2 for overview). In many places natural vegetation has been converted into irrigated agricultural plots. On the other hand in many areas, natural vegetation degraded or fragmented into desert or semi-desert areas. Both trends can clearly be observed in the left and middle panes of figure 8. For a NDVI $I_{c}$ threshold of 0.05 almost the complete ROI underwent an increase or decrease in $\mathrm{NDVI}_{\mathrm{c}}$. A relatively small area remains unchanged with respect to the NDVI.

Figure 8. Illustration of NDVI image differencing for a NDVI $I_{c}$ threshold of 0.05. Left pane: CORONA NDVI ${ }_{c}$ image of the Tarim downstream area (1964). Middle pane: LANDSAT ETM image for the same ROI (2007). Right pane: Difference map between both images, with the zones with or without change in $\mathrm{NDVI}_{\mathrm{c}}$ indicated according to the colour legend. Green indicates an increase in $\mathrm{NDVI}_{c}$, and Red a decrease. Yellow means no change in $\mathrm{NDVI}_{\mathrm{c}}$ within a threshold of 0.05 . 


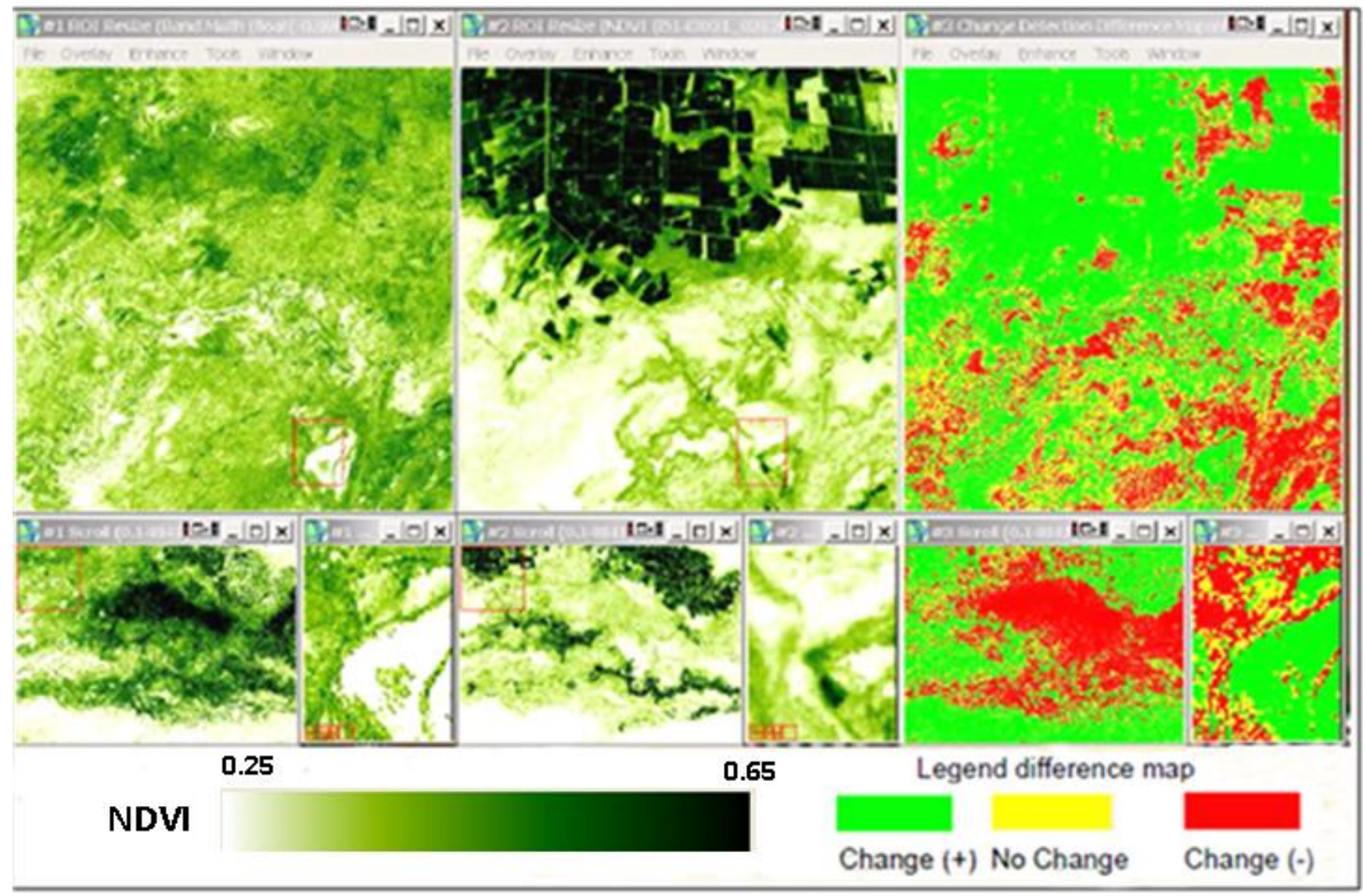

\subsection{Determination of the NDVI threshold}

An important aspect when considering land use change using image differencing based on the $\mathrm{NDVI}_{\mathrm{c}}$ is the threshold value which is selected to discriminate between a change or no change in the NDVI of a certain land use class. This is clearly illustrated by the data presented in table 4 .

Table 4. Percentage area change in function of different $\mathrm{NDVI}_{\mathrm{c}}$ thresholds.

\begin{tabular}{|c|c|c|c|c|c|}
\hline $\begin{array}{c}\text { Percentage change of } \\
\text { total ROI surface } \\
\text { NDVI threshold }\end{array}$ & Unclassified & Change $(-)$ & No Change & Change (*) & Total \\
\hline 0,050 & 0.0 & 41.9 & 13.0 & 45,0 & 100 \\
\hline 0.075 & 0.0 & 38.9 & 20.4 & 40.7 & 100 \\
\hline 0.100 & 0.0 & 35.9 & 28.6 & 35.4 & 100 \\
\hline 0.125 & 0.0 & 33.1 & 37.7 & 29.2 & 100 \\
\hline 0.150 & 0.0 & 30.3 & 48.7 & 23.0 & 100 \\
\hline 0.200 & 0.0 & 25.3 & 80.8 & 13.8 & 100 \\
\hline
\end{tabular}


The result shown in table 4 , indicate the requirement for a criterion enabling the selection of a physically based $\mathrm{NDVI}_{\mathrm{c}}$ threshold value. To be able to determine this $\mathrm{NDVI}_{\mathrm{c}}$ threshold, its value must be underpinned by leaf and canopy radiative transfer modelling with a coupled version of the PROSPECT and SAIL models.

A bio- geophysical boundary condition allowing for the quantification of significant changes in land use by its NDVI, is the ability to measure LAI differences of minimally 0.1 . Conformity with this boundary condition signifies that a $\mathrm{NDVI}_{\mathrm{c}}$ threshold of 0.05 is imperative. Given this boundary condition, land use change statistics based on a $\mathrm{NDVI}_{\mathrm{c}}$ threshold of 0.05 , are considered as plausible for land use change mapping based on diachronic image differencing.

Figure 9 is the result of a SAIL-PROSPECT simulation of a Gobi sagebrush canopy for different chlorophyll contents and a bright soil. The NDVI change statistic presented in table 4 using a $\mathrm{NDVI}_{\mathrm{c}}$ threshold of 0.05 is the most plausible interpretation of the magnitude of the NDVI changes which took place in the downstream area of the Tarim river basin during the last 44 years.

Natural vegetation and grassland degraded into desert and semi-desert areas or were converted into irrigated cropland. Both trends can clearly be observed over the time period mentioned. For a $\mathrm{NDVI}_{\mathrm{c}}$ threshold of 0.05 almost the complete province underwent an increase or decrease in $\mathrm{NDVI}_{\mathrm{c}}$. A relatively small area (13\%) of the Tarim downstream area has remained unchanged during the course of 44 years.

Figure 9. NDVIc in function of LAI and leaf chlorophyll content $\left[\mu \mathrm{g} / \mathrm{cm}^{2}\right]$. Runs were performed with the coupled PROSPECT - SAIL radiative transfer models using bright soils.

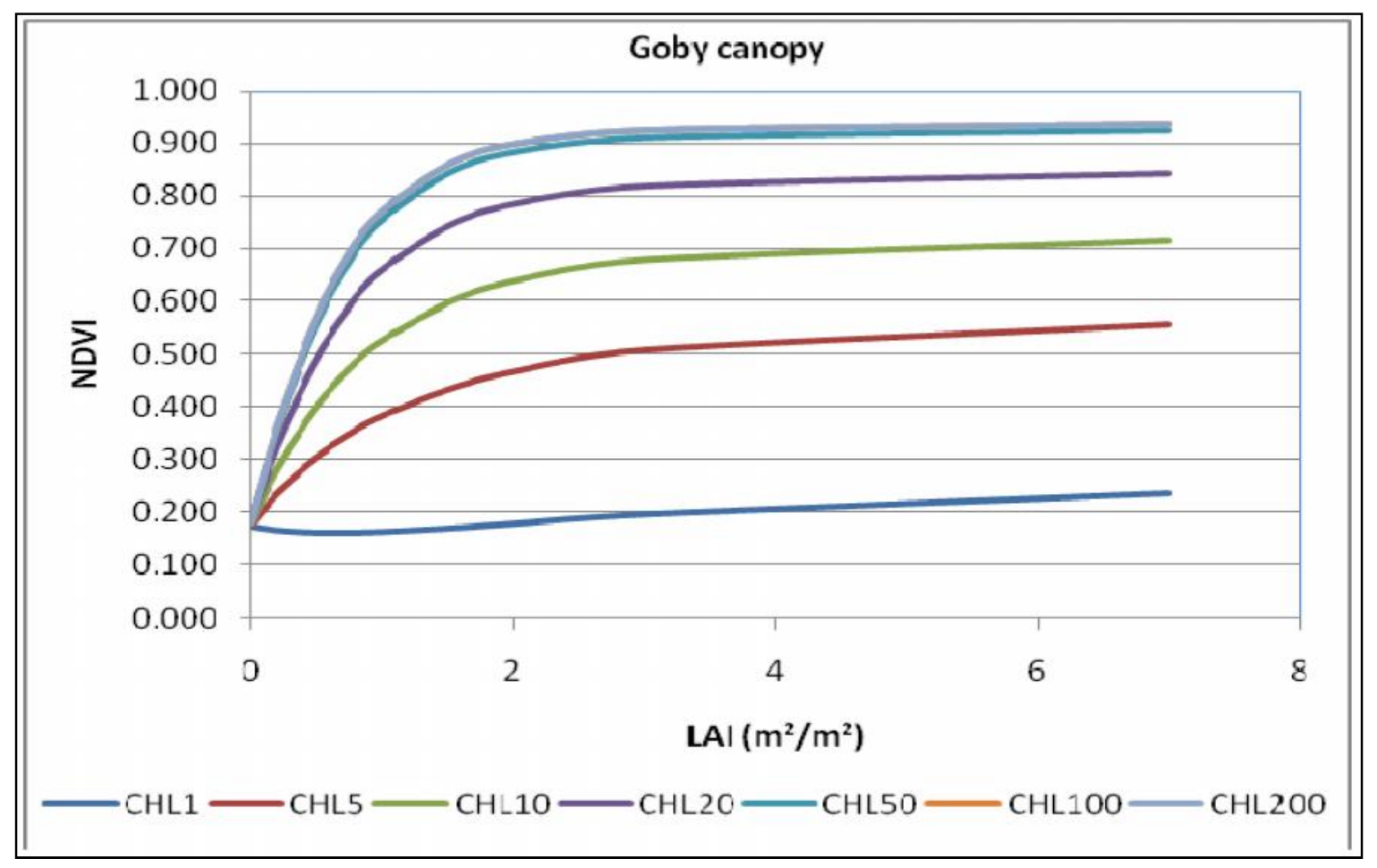




\section{Conclusions}

Over a time lapse of 44 years, a drastic change in land use took place in the downstream reaches of the Tarim river basin. In many places natural vegetation was converted into irrigated agricultural plots or alternatively, degraded and fragmented into desert or semi-desert.

With a $\mathrm{NDVI}_{\mathrm{c}}$ threshold of 0.05 almost the complete downstream Tarim ROI, underwent an increase or decrease in NDVI $I_{c}$. Very few areas remained unchanged. This resulted in the estimation over the last 44 years of a $45 \%$ increase in arable land, but concomitantly a $42 \%$ increase in desert and semi-desert areas. Only $13 \%$ of the region of interest remained unchanged (table 4 ).

Ruelland et al. [10] used CORONA imagery to produce diachronic maps of a $100 \mathrm{~km}^{2}$ stretch in the Sahel zone and concluded that:"A 50-year trend in LUCC led to a large increase in cropland but equally as well in an increase of eroded surfaces and desert land with sparse vegetation and a drastic reduction in woody cover". This observation of Ruelland et al. [10] over the same time frame as in this study, is very comparable to the observation made in the Tarim downstream area LUCC study in the Xinjiang province.

Since the revisit frequency of CORONA is very low, the dynamical aspects of past vegetation changes are limited to snapshots in time. Hence, it is impossible when using CORONA observations, to describe the dynamics of LUCC for a pre-defined ROI in great multitemporal detail.

Disturbance is an event that significantly alters the pattern of variation in the structure or function of an (eco)system. Fragmentation is the breaking up of a habitat, ecosystem, or land-use type into smaller parcels (Forman et al., 1995 [14]). Disturbance is generally considered a natural process. Fragmentation causes land transformation, an important process in landscapes as development occurs. An important consequence of repeated clearing (whether by natural disturbance or human activity) is that a continuous land cover can break down into isolated patches. This happens when the cleared area exceeds a critical level, beyond the critical level, landscapes transfer from a connected phase to a disconnected one (Green et al., 2006 [15]).

It goes without saying that the radiation regime and especially the hydrology of the the Xinjiang province has changed significantly over the last 44 years due to the impressive land use change observed and an the increased fragmentation of the original landscape from the sixties onward. During the period mentioned, the Tarim river retracted upstream, for several hundreds of $\mathrm{km}$, leaving behind desert land, inapt for agriculture and hence inapt to sustain human life. Evidently, this has led to large displacements of farmer families to other villages or middle sized cities. Concluding one can state that the observed LUCC has led to a larger hydrological, agricultural and ecosystem instability, an increased desertification and soil salinification and hence a decrease in biodiversity. Clearly these observations are not unique for the province of Xinjiang and its downstream Tarim river area, but for many semi-desert regions on the globe.

\section{Acknowledgements}

The authors wish to thank the Ministry of Science and Technology (MOST) of China as well as BELSPO, the Belgian Science Policy Office for the financial support received to execute the work described in this paper. We also acknowledge the work performed by the anonymous reviewers and co-authors, to enhance the scientific quality of this research paper. The research presented in this paper 
is supported by the "973 program" (No. 2009CB421301), the National Key Technology Programme (No. 2007BAH12B03) and the National Natural Science Foundation of China (No. 40730633 and No 0571030).

\section{References}

1. Turner, B.L., W.C. Clark, R.W. Kates, J.F. Richards, J.T. Mathews, and W.B. Meyer eds. 1990. The Earth as Transformed by Human Action. Cambridge University Press, New York.

2. Foley, J.A., R. DeFries, G.P. Asner, C. Barford, G. Bonan, S.R. Carpenter, F.S. Chapin, M.T. Coe, G.C. Daily, H.K. Gibbs, J.H. Helkowski, T. Holloway, E.A. Howard, C.J. Kucharik, C. Monfreda, J.A. Patz, I.C. Prentice, N. Ramankutty, and P.K. Snyder. Global consequences of land use. Science 2005; 309: 570-574.

3. Lepers, E., E.F. Lambin, A.C. Janetos, R. DeFries, F. Achard, N. Ramankutty, and R.J. Scholes. A synthesis of information on rapid land-cover change for the period 1981-2000. Bioscience 2005; 55: 115-124.

4. Robert McDonald, ed., In: Corona: Between the Sun \& the Earth, The First NRO Reconnaissance Eye in Space. Bethesda, Published by MD: ASPRS, 1997. ISBN 1-57083-041-X.

5. US Geological Survey, Earth Resources Observation and Science (EROS) Data Center , http://eros.usgs.gov/\#/Find_Data/Products_and_Data_Available/Declassified_Satellite_Imagery_1 .

6. Jacquemoud S. and Baret F. PROSPECT: a model of leaf optical properties spectra. Remote Sensing Environ 1990; 34: 75-91.

7. Verhoef W. Light scattering by leaf layers with application to canopy reflectance modelling: the SAIL model. Remote Sens. Environ 1984; 16: 125-141.

8. Tariq Aftab, M. Masroor A. Khan, Mohd. Idrees, M. Naeem. Effects of Aluminium Exposures on growth, Photosynthetic Efficiency, Lipid peroxidation, Antioxydant enzymes and Artemisinin Content of Artemisia Annua L. Journal of Phytology 2010; 2(8): 23-37.

9. Nagler P. L., Daughtry, C. S. T. and Goward S. N.. Plant Litter and Soil Reflectance. Remote Sens. Environ., 2000; 71: 207-215.

10. Ruelland, D., Tribotte, A., Puech, C., Dieulin, C.. Comparison of methods for LUCC monitoring over 50 years from aerial photographs and satellite images in a Sahelian catchment. International Journal of Remote Sensing, 2011; 32(6), 1747-1777.

11. Rouse, J. W., R. H. Haas, J. A. Schell, and D. W. Deering. 'Monitoring vegetation systems in the Great Plains with ERTS', Third ERTS Symposium, 1973, NASA SP-351 I, 309-317.

12. Kriegler, F.J., Malila, W.A., Nalepka, R.F., and Richardson, W.. 'Preprocessing transformations and their effects on multispectral recognition.' Proceedings of the Sixth International Symposium on Remote Sensing of Environment, 1969; p. 97-131.

13. Liming Zhou, Robert E Dickinson, Yuhong Tian, Jingyun Fang, Qingxiang Li, Robert K. Kaufmann, Compton J Tucker, Ranga B. Myneni. Evidence for a significant urbanization effect on climate in China. School of Earth and Atmospheric Sciences, Georgia Institute of Technology, Atlanta, GA 30332, USA. Proceedings of the National Academy of Sciences of the United States of America. 07/2004; 101(26): 9540-4. DOI: 10.1073/pnas.0400357101. 
14. Forman, R.T.T. Land Mosaics: The Ecology of Landscapes and Regions. 1995. Cambridge University Press, Cambridge, UK.

15. Green, D.G., Klomp, N.I., Rimmington, G.R. and Sadedin, S. 2006. Complexity in Landscape Ecology, Springer, Amsterdam.

$$
\text { (C) } 2011 \text { by the authors; licensee Insciences Journal. }
$$

Open Access article under the terms and conditions of Creative Commons Attribution Non-Commercial License 3.0 Unported. 